\title{
LA INSINVATIO COMO RECURSO DE SUBVERSIÓN AXIOLÓGICA EN EL PROEMIO DE LISIAS III
}

\author{
Jesús Hernández Lobato y Óscar Prieto Domínguez \\ Universidad de Salamanca - Universidad de Valladolid \\ parvuslupus@hotmail.com - praxo@yahoo.es

\section{THE INSINVATIO AS RESOURCE OF AXIOLOGICAL SUBVERSION IN THE PROEM OF LYSIAS III}

Este artículo se propone analizar los mecanismos rectores de uno de los recursos persuasivos más lábiles y sutiles de la Retórica antigua: la insinuatio. Para ello, se toma como ejemplo el proemio de Lisias III, por tratarse de un discurso apologético encuadrable dentro del turpe genus, es decir, el grado mínimo de defendibilidad de una causa. Lisias debe dar la vuelta a los prejuicios del jurado con una cuidada captatio beneuolentiae, que evite la alusión directa a los muchos puntos flacos de su cliente. Su proemio se basa enteramente en una retórica negativa o del silencio, característica de la insinuatio: los métodos tácitos de persuasión y una sutil pragmática de las implicaturas consiguen influir en el subconsciente del auditorio y alterar la polaridad de sus prejuicios mediante un juego implícito de identificaciones con determinadas instancias ficcionales emanadas de la polifonía del discurso. Dissimulatio e insinuatio se aúnan para dar forma a una retórica de lo no proferido, una suerte de oratoria negativa cuyo detenido estudio revela una incuestionable modernidad.

Palabras clave: Lisias; insinuatio; retórica negativa; recursos persuasivos emocionales; proemio; discurso de defensa; dissimulatio; retórica del silencio, genus iudici.
This paper aims to analyse the guiding mechanisms behind one of the most evasive and subtle persuasive resources of ancient Rhetoric: the insinuatio. To this end, we take the proemium of Lysias III as an ideal example: in fact, this defence speech can be placed within the turpe genus, that is to say, the lowest degree of defensibility. Lysias has to cause a volte-face in the Jury's prejudices by means of a thorough captatio beneuolentiae, avoiding any direct allusion to his client's many weak points. Lysias' proemium is entirely based on a negative or silent rhetoric, which is typical of insinuatio: these tacit means of persuasion and a subtle pragmatics of implication enable Lysias to influence the subconscious of his audience and change the polarity of their many prejudices. All these goals can be achieved by means of an implicit game of identification with certain fictional entities emanating from the polyphony of the speech. Dissimulatio and insinuatio come together in order to shape a rhetoric of non-utterance, a kind of negative oratory, whose unquestionable modernity could be easily revealed by a careful study.

Keywords: Lysias; insinuatio; negative rhetoric; emotional persuasive resources; preface; defence speech; dissimulatio; rhetoric of silence; genus iudiciale. 
«Aber das ist ja gerade der Sinn der öffentlichen Meinung, die die Presse herstellt, die Öffentlichkeit unfähig zum Richten zu machen, die Haltung des Unverantwortlichen, Uninformierten ihr zu suggerieren».

(Walter Benjamin, «Karl Kraus», Gesammelte Schriften II/1, Fráncfort, 1971, p. 335)

La retórica, en tanto que arte (técnica) de la persuasión, consta de un sinfín de artimañas destinadas a conseguir que el oyente se convenza de la verdad de las palabras del orador y acceda a lo que éste propone en su discurso. Sin duda alguna, son muchas las similitudes de la retórica con el arte del amor, orientado igualmente a persuadir al destinatario de este sentimiento de que otorgue su aquiescencia. Más que nunca, ambas realidades se

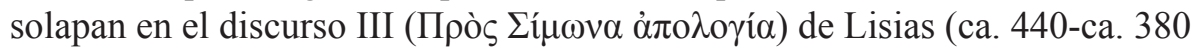
a. C. ${ }^{1}$ ). Tanto en el proceso del cortejo amoroso, como en la captación de la benevolencia del auditorio desempeña un papel importantísimo la insinuatio, un recurso a menudo desatendido que articula todo el proemio del citado discurso lisiaco ${ }^{2}$.

Se trata de un discurso de defensa ante un tribunal, por lo que se enmarca

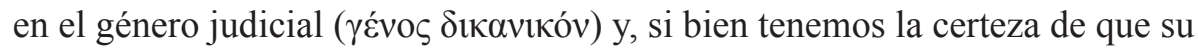
composición se debe al brillante orador ateniense, nada sabemos de su cliente - ni siquiera el nombre-. Éste, de acuerdo con la constitución ateniense, debía hacerse cargo de su propia defensa y pronunciar él mismo su discurso ante los jueces: por lo tanto, ya que la memorización ( $\mu v \eta ́ \mu \eta$ o memoria) y la actio (نં óкрıбıৎ) dependían enteramente de la habilidad del propio implicado, no es de extrañar que el resto de los oficios del orador (que atañen a la composición del discurso) le fueran confiados a un profesional como Lisias, capaz de construir una defensa sólida y persuasiva siguiendo los cánones de la retórica.

${ }^{1}$ Un resumen, conciso pero completo, de su biografía puede encontrarse en G. Kennedy, A new History of Classical Rhetoric, New Jersey, 1994, pp. 65-67.

${ }^{2}$ Lejos ha quedado ya la convicción de K. J. Dover, Lysias and the Corpus Lysiacum, Berkeley-Los Ángeles, 1968, de que el único discurso del Corpus Lysiacum enteramente escrito por Lisias fuera el XII, por lo que, a nuestros ojos, se antoja evidente que el discurso III es fruto de la mano de este genial orador. En lo que a nuestro discurso propiamente se refiere, cf. F. Cortés Gabaudán, «La Retórica aristotélica y la oratoria de su tiempo (sobre el ejemplo de Lisias III)», Emerita 66, 1998, pp. 339-359. 
La fecha del proceso se puede situar en torno al 392 a. C., por las referencias que se hacen, avanzado el discurso (45), a las batallas de Corinto y Coronea, disputadas en el año 394 a. C. ${ }^{3}$

El proceso tiene lugar ante el Areópago, tribunal profesional compuesto

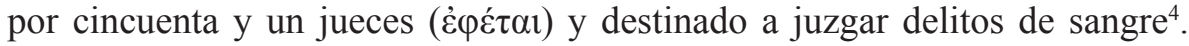
En efecto, la acusación que pesa sobre el cliente de Lisias es una acción

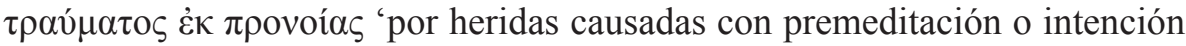
de matar', y los cargos han sido presentados por su rival Simón. Para que se entienda mejor la situación penal del acusado, resumiremos brevemente los hechos que lo han llevado ante los tribunales.

El acusado, cuyo nombre desconocemos, es un hombre honorable, con posibilidades económicas y edad ya algo avanzada, que se enamora de un jovencito de Platea, posiblemente un esclavo o algo similar, llamado Teódoto. Pero también pugna por los favores del muchacho un tal Simón, una persona vulgar, con pocos recursos económicos, tendente a la embriaguez y a la violencia. En la disputa por el muchacho tienen lugar varios episodios violentos (según el discurso hay un total de cuatro enfrentamientos, mayoritariamente propiciados por Simón). Como resultado del último de ellos resultan heridos tanto el acusado como Simón. El asunto parece quedar zanjado, pero, cuatro años después de suceder los hechos, Simón acusa a su rival ante el Areópago. Animado, según el acusado, por el mal papel que hizo éste en un reciente proceso privado sobre una antídosis, Simón alega que, en uno de estos incidentes violentos, el acusado acudió armado con un fragmento de cerámica a su propia casa, $\mathrm{y}$, habiéndole declarado su intención de matarlo, le causó varias heridas con dicha arma. Además, según Simón, Teódoto estaba ligado a él por un contrato que habría quedado irregularmente roto cuando se fue con el acusado. Éstos son los pilares del discurso de acusación que pronunciaría Simón ante el Areópago.

El acusado se juega el exilio y la pérdida de todos sus bienes, sanciones previstas para ese tipo de delitos. Además, su prestigio personal ha quedado

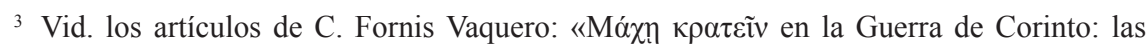
Batallas Hoplíticas de Nemea y Coronea (394 a. C.)», Gladius 23, 2003, pp. 141-159; «La Guerra de Corinto (395-386 a. C.): una Aproximación a las Fuentes», Polifemo 2004, pp. 178 186; así como su reciente y exhaustiva monografía: La Guerra de Corinto. Fuentes Antiguas e Historiografia Moderna, Oxford, 2007.

4 Vid. R. W. Wallace, The Areopagos Council to 307 b. C., Londres, 1985; y el más actualizado O. de Bruyn, La compétence de l'Aréopage en matière de procès publics, Stuttgart, 1995. 
gravemente dañado no sólo por la acusación de Simón, sino también por el oprobio añadido de la divulgación de sus relaciones con el joven esclavo. No es, pues, de extrañar que recurra a los servicios de un orador de prestigio, Lisias, de quien se dice que sólo fue derrotado en dos ocasiones.

La grandeza de este discurso depende, además de su belleza formal y perfección retórica, de la increíble habilidad con la que Lisias consigue elaborar una defensa persuasiva para una causa tan difícil de defender como ésta, dada la hostilidad inicial de todos los jueces contra el acusado. La posición de éste parece, en principio, poco defendible, considerando el sinfín de elementos desprestigiantes que recaen sobre ella. En primer lugar, la acusación de intento de asesinato tiene un peso ya de por sí más que considerable. A esto hay que sumar el bochorno y la deshonra de sacar a la luz pública las relaciones amorosas del acusado, un hombre ya maduro y supuestamente sensato, un ciudadano acaudalado y probo, con un esclavo mucho más joven que él y de muy baja condición (si hubiera sido un muchacho de posición distinguida no recaería sobre el acusado este tabú social)5. Además, este amor plebeyo le ha llevado a actuar insensatamente y mezclarse con personajes de los bajos fondos como Simón, involucrándose en varias peleas callejeras. No es raro que el acusado desechara en su momento la idea de llevar a juicio a Simón y pasara por alto sus afrentas, con tal de librarse de la vergüenza de relatar ante un tribunal hechos personales tan denostados socialmente. No debemos olvidar que, en el momento del juicio, el acusado ya ha sufrido el descrédito (además del empobrecimiento) que le reportó la pérdida de un reciente pleito sobre una antídosis, situación que, como sabemos, aprovechó Simón para poner su denuncia. A esto se suma el hecho de que el discurso de acusación siempre precedía al de defensa, por lo que Simón, en el momento

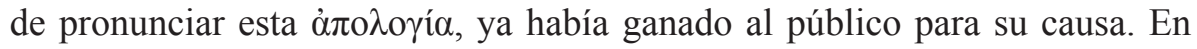
este punto, el auditorio ya se hallaba cansado de escuchar argumentaciones, y el aburrimiento, unido a la hostilidad contra el acusado, hacían especialmente difícil la persuasión del jurado. Por último, el tribunal del Areópago parece una plaza más difícil de conquistar, pues sus jueces estaban más preparados,

${ }^{5}$ Mucho se ha escrito sobre la concepción que de la vida sexual tenían los griegos, pero a todas luces permanecen insuperadas, por su acercamiento multidisciplinar, las monografías de M. Foucault y E. Cantarella sobre el particular, cf. M. Foucault, Historia de la sexualidad, México (vol. 1: La voluntad del saber, 1992; vol. 2: El uso de los placeres, 1993; vol. 3: La inquietud de sí, 1987); E. Cantarella, Según natura. La bisexualidad en el Mundo Antiguo, Madrid, 1991. 
eran menos sensibles a la adulación ${ }^{6}$ y prohibían terminantemente aducir elementos ajenos a la causa concreta que se estuviese exponiendo.

Todo esto permite clasificar el presente caso en el $\pi \alpha \rho \alpha ́ \delta$ o que Quintiliano ${ }^{7}$ traduce como genus admirabile y el auctor ad Herennium ${ }^{8}$ como turpe genus, es decir, el grado mínimo de defendibilidad de una causa. Este genus requiere un enorme talento retórico y persuasivo, ya que el orador debe enfrentarse a un público de entrada hostil y predispuesto contra su causa, intentando darle la vuelta a sus prejuicios y atraer poco a poco su benevolencia, para lo cual resultan decisivos los primeros minutos de su intervención. Es precisamente por esto por lo que el presente proemio supone un maravilloso ejemplo del hábil manejo de los recursos retóricos más sutiles, capaces de invertir el contexto más desfavorable y lograr persuadir sin aparentarlo. Sobre este supuesto hemos de basar necesariamente el análisis retórico. Procedamos ${ }^{9}$ :

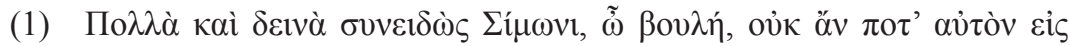

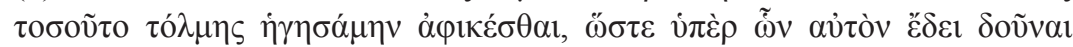

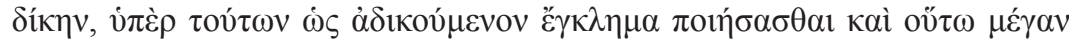

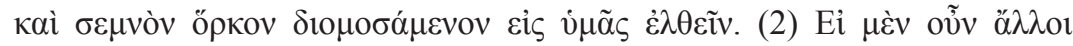

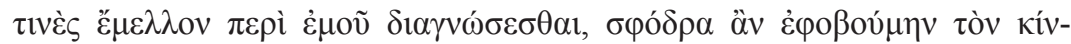

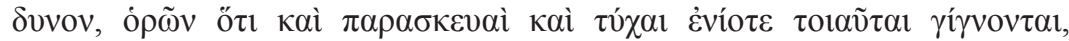

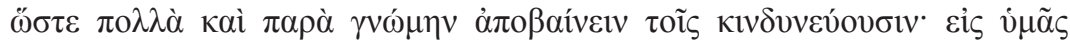

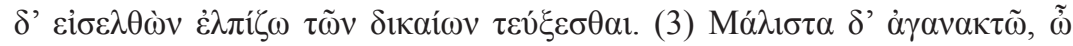

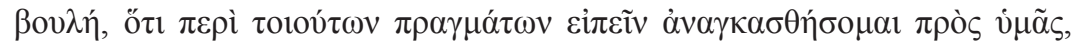

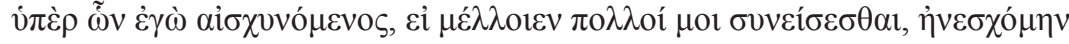

${ }^{6}$ La adulación de los jueces, en tanto que recurso de la captatio beneuolentiae del tribunal, era considerada imprescindible por los manuales de oratoria judicial de la época, vid. Rhetorica ad Alexandrum 36. Esta obra, de atribución incierta, convencionalmente se atribuye al rétor Anaxímedes de Lámpsaco: cf. M. Fuhrmann, Anaximedes. Ars Rhetorica, Leipzig, 1966.

Inst. Or. IV 1.40. Cf. la edición de M. Winterbottom, Quintiliani Institutionis oratoriae Libri duodecim, 2 vols., Oxford, 1970.

8 Rhet. ad Her. I 3.5. La edición más reciente de la Rhetorica ad Herennium corre a cargo de Th. Nüsslein, Rhetorica ad Herennium, Zúrich, 1994; mientras que una buena traducción al castellano puede encontrarse en S. Núñez, Retórica a Herenio, Madrid, 1997. Muy actualizado y útil resulta el ya clásico estudio de F. L. Müller, Kritischen Gedanken zur antiken Mnemotechnik und zum «auctor ad Herennium», Stuttgart, 1996.

9 Seguimos la edición de C. Hude, Lysiae orationes, Oxford, 1912. La traducción al castellano es nuestra. 


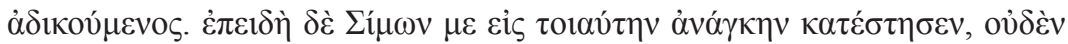

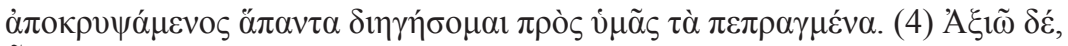

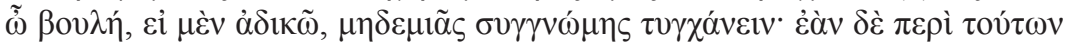

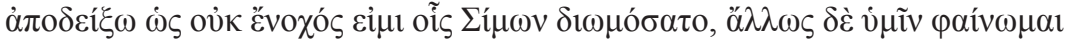

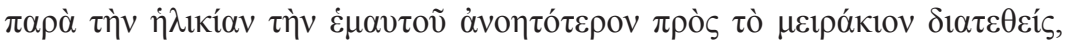

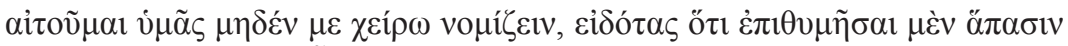

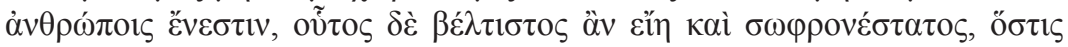

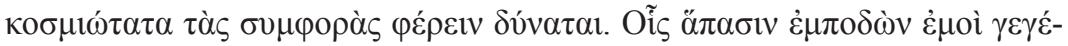

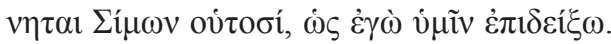

(1) Con las muchas y terribles cosas que sé de Simón, consejeros, jamás pensé que llegaría a tal grado de osadía como para ser el acusador, en calidad de ofendido, en un asunto por el que debería él pagar una pena ${ }^{10}, \mathrm{y}$ presentarse así ante vosotros tras ofrecer un juramento grande y solemne. (2) Pues bien, si fueran otros los que fuesen a enjuiciarme, mucho temería el peligro, al ver que a menudo se producen tales intrigas y circunstancias, que les sobrevienen a los acusados muchos otros cargos que no se esperaban. Pero, al venir ante vosotros, espero obtener justicia. (3) Lo que más me indigna, consejeros, es que me veré obligado a hablaros de asuntos tales, que, por vergüenza de que fueran conocidos por muchos además de mí, soportaba para mis adentros, aun siendo yo la víctima. Dado que Simón me ha puesto en tal aprieto, sin ocultar nada os relataré todo lo sucedido. (4) Y os pido, consejeros, que si soy culpable, no tengáis ninguna compasión; pero si demuestro que no estoy relacionado con el juramento de Simón sobre este asunto, y os parece que tengo una disposición hacia el joven más insensata de la que corresponde a mi edad, os pido que no me consideréis peor. Sabéis que la disposición a enamorarse reside en todos los hombres, y que el más prudente y el mejor sería el que puede soportar las desgracias con la mayor elegancia. En todo esto ha resultado un impedimento para mí Simón, el aquí presente, como voy a demostraros.

\section{Comentario retórico: insinuatio y prejuicio}

De las tres funciones tradicionalmente atribuidas al proemio (iudicem attentum parare, iudicem docilem parare y iudicem beneuolum parare) ${ }^{11}$, el

\footnotetext{
${ }^{10}$ Para la traducción de los términos propiamente jurídicos en el corpus lysiacum resulta útil la consulta de la obra de L. López Villar, Léxico jurídico de Lisias, Granada, 1992.

${ }^{11}$ Sobre el origen de estas funciones vinculadas a la parte inicial del discurso, cf. F. Cortés Gabaudán, «Origen de las funciones del proemio y de las cualidades de la narración», Actas
} 
que ahora nos ocupa se centra casi exclusivamente en la captatio beneuolentiae o, por usar una terminología griega, en la consecución de la cưvor $\alpha$. ¿A qué se debe esto? A la necesidad de modificar radicalmente los afectos del público, y moverlo a una postura favorable a la nuestra. Si esto resulta importante en cualquier caso, cuando nos enfrentamos a uno perteneciente al $\pi \alpha \rho \alpha ́ \delta$ o ov $_{\sigma} \chi \tilde{\eta} \mu \alpha$ se convierte en imprescindible y determinante para la buena marcha de la causa.

Del mismo modo, lograr la દűvora supone algo esencial en los discur-

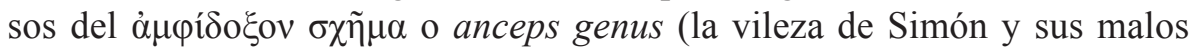
hábitos podrían equilibrar de algún modo la balanza de la defendibilidad de ambas causas), sólo que para ellos se precisará una menor sutileza persuasiva que en el $\pi \alpha \rho \alpha ́ \delta$ o ov, que deberá recurrir a lo que tradicionalmente se conoce como insinuatio. En palabras de C. Quirio Fortunaciano (Artis Rhetoricae Libri III, II 13)12: Quid in amphidoxo? Beniuolum, sed ita ut ab eo quod turpe est ad id quod honestum est eum auocemus; quid in paradoxo? Beniuolum per insinuationem.

El proemio habrá de servirse, así pues, continuamente del recurso de la insinuatio (el más apropiado para el genus turpe), que según Heinrich Lausberg «consiste en que mediante una astuta utilización de los recursos psicológicos (suposición, imputación, sorpresa, incluso algún rasgo ingenioso) influimos sobre el subconsciente del público en un sentido favorable a nuestra causa $\mathrm{y}$, de esa manera, poco a poco vamos preparando el terreno para captar su simpatía» ${ }^{13}$.

A continuación veremos como Lisias emplea estos recursos para captar la benevolencia de los jueces, sirviéndose de lo que Aristóteles denomina i $\alpha \tau \rho \varepsilon v ́ \mu \alpha \tau \alpha$ (Arist., Rh. 1415²5) o remedios para paliar las carencias del auditorio y su hostilidad. Lisias desarrolla en su discurso tres de los cuatro modos de conseguir la cúvoı $\alpha$ propuestos por Aristóteles (Arist., Rh. 1415 a):

del VII Congreso Español de Estudios Clásicos (Madrid, abril de 1987), Madrid, 1989, vol. II, pp. 135-140. Para un análisis morfológico de los exordios construidos por nuestro orador ático, vid. P. Grau, Die Proemiengestaltung bei Lysias, Würtzburg, 1971 (tesis doctoral).

${ }^{12}$ Cf. C. Chirii Fortunatiani Artis rhetoricae libri III editado por C. Halm, Rhetores Latini Minores, Leipzig, 1863, pp. 79-134. Los compendios escritos por Fortunaciano y que hoy en día denominamos Artis rhetoricae libri III constituyeron la fuente principal de Casiodoro para el aprendizaje de la retórica y la base de la educación medieval. Vid. T. M. Conley, Rhetoric in the European Tradition, Chicago, 1990; V. Florescu, La rhétorique et la néorhétorique. Genèse - Évolution - Perspectives, París-Bucarest, 1982.

${ }^{13}$ H. Lausberg, Manual de Retórica, vol. I, Madrid, 1983, p. 255. 


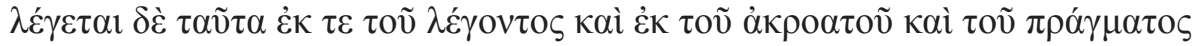

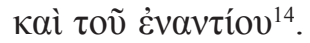

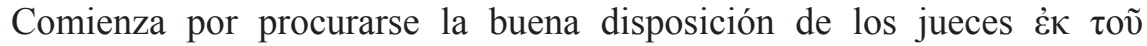
Ėvavtíov, es decir, a partir del desprestigio de su adversario. Este recurso parece útil con un adversario sumamente desprestigiable como Simón y, en el mejor de los casos, llevaría a equilibrar un poco la balanza respecto a la denostada postura del acusado. Sin embargo, esta uituperatio no resulta del todo sencilla: Simón, que ha hablado antes, ya se ha granjeado el afecto del público, y un excesivo encono en la crítica podría producir efectos contrarios a los esperables. Además, como sabemos, en el Areópago no estaba permitido recurrir a los elementos ajenos al caso, por lo que no podía denunciar explícitamente el pasado delictivo de Simón. Se hace imprescindible la técnica de la insinuatio: las fechorías del acusador se sugieren ya desde el mismo momento de tomar la palabra, dejando caer que han sido muchas y terribles, pero se hace de un modo indirecto, sin especificar cuáles han sido, dejando a la imaginación de los jueces esa tarea (que en la mente de cualquiera

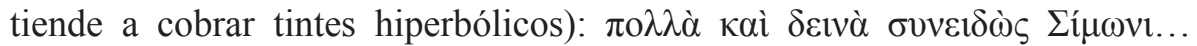
Inteligentemente, Lisias se sirve de una estructura binaria de adjetivos de fuerte carga semántica para comenzar su discurso, lo que, además de atraer la atención del auditorio con su rotunda sonoridad rítmica, consigue encarecer los vicios de la parte contraria con una formulación sintética pero efectiva. De todas esas faltas comienza considerándose sabedor ( $\sigma v v \varepsilon 1 \delta \omega ́ \varsigma)$, y el hecho de que, conociéndolas, no las publique (al menos en teoría) provoca un movimiento de simpatía inconsciente en el jurado, mediante el contraste implícito entre la actitud tolerante y conciliadora del acusado y la lluvia de acusaciones y vituperios que acababa de verter contra él Simón en el discurso. Así, silenciando los defectos de Simón, los encarece y, aceptando sumisamente su papel de acusado, se erige en acusador y cambia la dirección del debate.

El acusado toma la actitud de un ingenuo, de un hombre honrado, incapaz de sospechar las cotas de malicia que había llegado a alcanzar su acusador, si

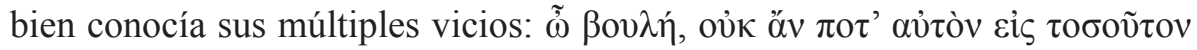

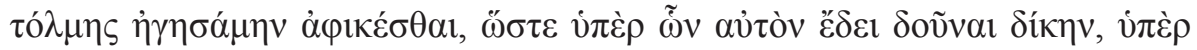

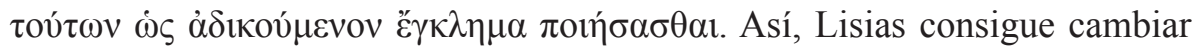
las tornas y lograr presentar a su cliente como víctima de las ambiciones de

\footnotetext{
${ }^{14}$ Vid. Aristóteles, Retórica. Introducción, traducción y notas de A. E. Ramírez Trejo, México, 2002 (edición bilingüe).
} 
Simón, oponiendo a la tó $\lambda \mu \eta$ de este último la inocente estupefacción de su defendido. Con esta actitud de «sincera» sorpresa puede denunciar, sin que

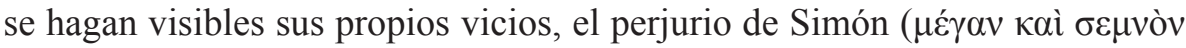

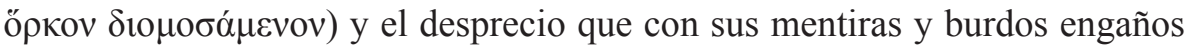
muestra hacia la inteligencia de los miembros del tribunal ${ }^{15}$. Hábilmente, ha unido en una sola oración los motivos de cólera que él tiene hacia Simón y los que debe sentir el tribunal por la ofensa implícita del menosprecio de sus miembros, identificando de esta manera la afrenta del acusador hacia su persona con la afrenta hacia los jueces. La finalidad de este recurso es doble: extender el alcance del juicio a una situación que afecta personalmente al conjunto del auditorio (tópico del tua res agitur) y provocar sentimientos de enemistad hacia el acusador. Este segundo recurso persuasivo es una de las tres $\pi i ́ \sigma \tau \varepsilon ı \varsigma$ que Aristóteles menciona en el libro I de su Retórica con el

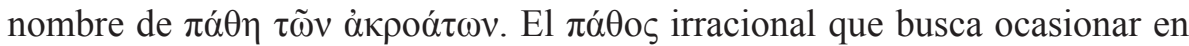
el alma de los jueces es la ira u óprí contra su adversario. Simón ya había movido la cólera del tribunal: la misión de este discurso de réplica es aprovecharla para cambiar su orientación y redirigirla, como si de un espejo se tratase, contra Simón, convirtiendo al acusador en acusado y al auditorio en pleno en víctima de su $\tau o ́ \lambda \mu \eta$. Y esto lo consigue con esa estudiada ingenuidad e indignación con la que comienza su intervención. La figura del acusado apenas está presente como tal, es una primera persona gramatical aún sin atributos humanos distintivos, en una especie de llamada anónima a la empatía

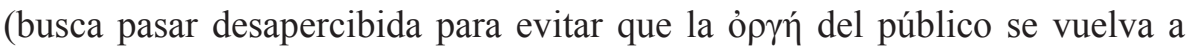
centrar en ella); por eso - amén de los motivos estéticos del sobrio aticismo de Lisias-, el discurso huye de llamativos recursos retóricos, inconvenientes para un caso como éste, del genus turpe. En esta primera parte, sólo se permite la cadencia de estructuras binarias en lo que atañe a los vicios de Simón, que, de esta manera, quedan enfatizados en medio de la austeridad general

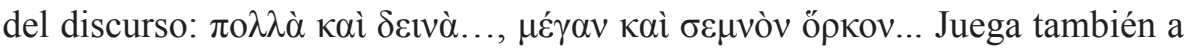
la contraposición de conceptos en construcción hipotáctica, dentro de un mis-

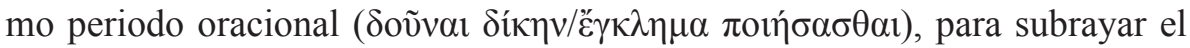
carácter trastocador de las acciones de Simón y obtener del jurado un cambio

\footnotetext{
${ }^{15}$ Los juramentos de este tipo fueron abolidos de la práctica judicial por Platón (Leyes 948d), ya que obligaban necesariamente a que una de las dos partes (bien la acusación, bien la defensa) cometiera un delito de perjurio.
} 
radical de posicionamiento respecto a los involucrados en la sentencia, dando un giro a los roles de reo y acusador.

En el segundo punto, busca la eưvot $\alpha$ a partir del halago de la capacidad de

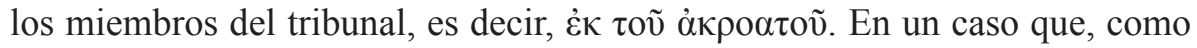
éste, se presentaba difícil para el acusado a causa del ambiente general de hostilidad hacia su persona, el halagar los oídos de los jueces con adulaciones y lisonjas era una baza imprescindible para cambiar las tornas del caso y ganarse su simpatía. Pero este recurso debe emplearse con cautela $-\mathrm{y}$ más en el caso del cliente de Lisias - ya que un exceso de celo en la alabanza podría dar la apariencia de ser pura demagogia, una técnica facilona para hacerse con el beneplácito del público, que podría sentirse ofendido si lo considera un insulto a su inteligencia. Por todo ello, este $\tau$ tó con ciertas prevenciones, máxime cuando el auditorio no está de entrada a favor de la persona que lo utiliza.

En realidad, el contenido de todo este parágrafo segundo no es sino una súplica tácita a los miembros del jurado para que actúen con imparcialidad (o, mejor aún, con benignidad) al enjuiciar su causa. Y digo que es tácita porque no la llega a formular como tal en todo el proemio (exigencia que hubiese estado mal vista dada la situación del acusado). ¿Cómo se las arregla para conseguirlo? Por la vía de la insinuatio y la pragmática de las implicaturas. Mostrando una total seguridad en el buen hacer del jurado ( $\varepsilon i \varsigma$ v $\mu \tilde{\alpha} \varsigma$

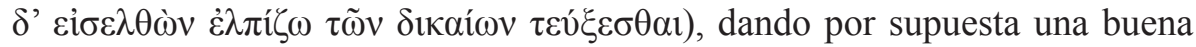
voluntad que no era tal y declarando no sentir el temor que en realidad siente

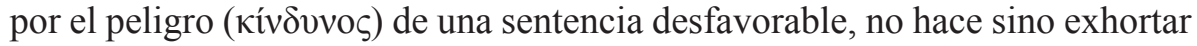
implícitamente al tribunal a que obre en consecuencia y se haga acreedor de la confianza que ha depositado en él. Así obtiene, sin pedirlo, el asentimiento de un jurado tocado en su vanidad, dispuesto a obrar de ese modo para mostrarse merecedor de las capacidades y saberes que se le suponen. En esto tiene un peso decisivo el procedimiento indirecto de alabanza que idea Lisias para su discurso: a sabiendas de que el tribunal estaba mal dispuesto contra su causa, de que la combinación de intrigas ( $\pi \alpha \rho \alpha \sigma \kappa \varepsilon v \alpha i ́)$ y azares (

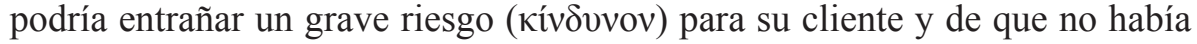
ninguna seguridad en una sentencia favorable, atribuye todo este cúmulo de circunstancias adversas (pero reales en aquel momento) al mal hacer como jueces y a la incapacidad personal de «otros» posibles jurados ( $\alpha \lambda \lambda$ $\lambda$ o $)$, que no cuentan con el carácter supuestamente imparcial y ecuánime del tribunal que en aquel momento presidía la sesión. Al trasladar las deficiencias efectivas 
del jurado a hipotéticas terceras personas ( $\alpha \lambda \lambda$ or) consigue que sus miembros las vean como tales, comprendan su injusticia y se sientan con capacidad de criticarlas o censurarlas como vicios ajenos, observados desde fuera con la severidad propia del que enjuicia los defectos de los demás, seguro de no poseerlos. Gracias a esta alienación o extrapolación de la situación presente, el tribunal adopta inconscientemente un patrón de conducta contrario al de los «otros», es decir, favorable al discurso del acusado, ecuánime y justo, como vía para halagar su vanidad y hacerse tributario de las lisonjas implícitas en esta parte del discurso.

En efecto, todo el contenido adulador se expresa in absentia, por el contraste implícito entre los vicios de los otros jurados (ö $\alpha \lambda \mathrm{ol})$ y las virtudes no explicitadas de éste ( $\dot{v} \mu \tilde{\alpha} \varsigma)$. El cambio de mentalidad opera mediante el juego de identificaciones con estas dos instancias discursivas: a los $\alpha \hat{\lambda} \lambda$ or se les atribuye lo que es, los inconvenientes y prejuicios reales de la situación efectiva del caso; al vjuã lo que debería ser, el contexto ideal para un juicio justo y la actitud requerida. El secreto está en lograr que los jueces, al identificarse con el $\tilde{v} \mu \tilde{\alpha} \varsigma$, actúen en consecuencia, den la espalda a su actitud presente y depongan sus defectos, considerándolos patrimonio de los otros ( $\left.\alpha^{\prime} \lambda \lambda \mathrm{or}\right)$. La alabanza es, pues, indirecta, implícita, por negación de las deficiencias de los otros, con lo que salva el peligro del exceso de la lisonja y la apariencia de demagogia. De nuevo triunfa la insinuatio.

Lisias recurre, como salta a la vista, a la técnica de la contraposición adversativa entre los dos periodos oracionales de este segundo parágrafo, como

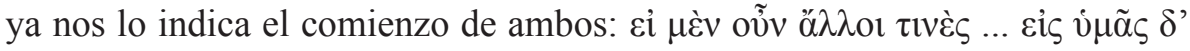

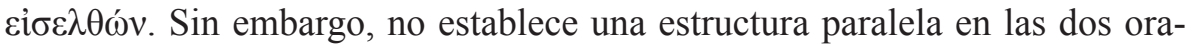
ciones que subraye su contraste, y se decanta por la uariatio, posiblemente para que el discurso y sus recursos persuasivos tan cuidadosamente sopesados no resulten excesivamente elaborados o artificiosos y llamen demasiado la atención de los jueces. Ya hemos mencionado más arriba la intención del acusado de pasar desapercibido, especialmente en un contexto tan adverso y espinoso para su honra, por lo que no es de extrañar que rehuya la ampulosidad estilística y los alardes retóricos, y opte por hacer gala de la «contención proemial», tan recomendable en estos casos.

Vuelve, eso sí, a decantarse por los ritmos binarios a la hora de encarecer

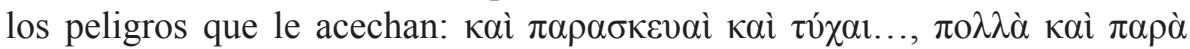
$\gamma v \omega ́ \mu \eta v$. En el primero de estos ejemplos es interesante, asimismo, señalar la coordinación doble de elementos semánticamente contradictorios pero prag- 
máticamente complementarios: las $\pi \alpha \rho \alpha \sigma \kappa \varepsilon v \alpha i ́$ (que podríamos traducir aquí por 'maniobras') designan los planes de actuación preparados de antemano, las intrigas o disposiciones que ya han sido tramadas cuidadosamente. Huelga

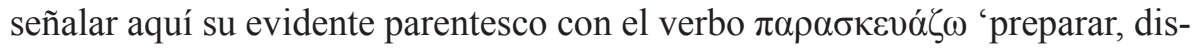

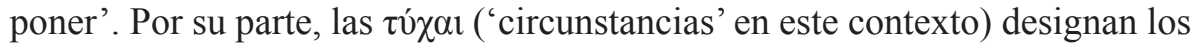
imponderables de todos los juicios, lo que escapa de todo preparativo, esos elementos azarosos que acaban determinando que la balanza se incline en una u otra dirección. Este binomio sintetiza todos los kívovvor a los que se enfrenta el acusado: por un lado, las asechanzas de Simón y sus disposiciones para encolerizar al auditorio contra él; por el otro, la especial circunstancia de desventaja en que se encuentra y la posible respuesta irracional del jurado (este último concepto queda reforzado más adelante con el sintagma $\pi \alpha \rho \grave{\alpha}$ $\gamma v \omega ́ \mu \eta v)$. Así, expresando su total despreocupación ante los peligros se puede permitir enumerarlos sin parecer manipulador: en pocas líneas aparece todo

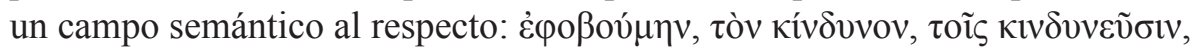
etc.

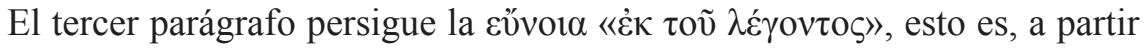
de la propia persona del que habla. Tras haber descubierto los vicios de su acusador (1) y haberse hecho con la atención de un tribunal halagado (2), emprende ahora la difícil labor de limpiar su imagen pública. Este cometido le ocupará toda la segunda parte del proemio (3-4), que puede considerarse en este sentido unitaria.

Para ello, expone su profundo enfado con el acusador ( $\dot{\alpha} \gamma \alpha v \alpha \kappa \tau \tilde{\omega})$, apelan-

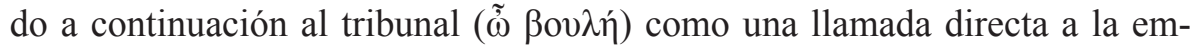
patía. En vez de ocultar la vergüenza, $\alpha i \sigma \chi v ́ v \eta$, que siente por los hechos en que se ha visto involucrado, opta por confesarla abiertamente a los jueces y hacerles partícipes de su bochorno, a sabiendas de que silenciarlo solamente habría servido para hacerlo mayor y más patente en la mente del auditorio. Lisias se da cuenta de que la credibilidad de su cliente en un juicio de tales características (clasificable, como hemos visto, dentro del genus turpe) depende casi enteramente de que asuma públicamente lo vergonzoso de la situación en que se encuentra, y se haga cargo de sus caras más impúdicas y polémicas, pues rehuir hablar de lo que ya ha salido a la luz desacreditaría todo el resto de su argumentación. Pero, sabiamente, focaliza toda la culpa de su vergüenza en la maldad de Simón, que con sus ardides le obliga a hacer público lo que nunca deseó que lo fuera, hasta el punto de pasar por alto sus numerosas afrentas con tal de no tener que dar cuenta de sus asuntos íntimos: 


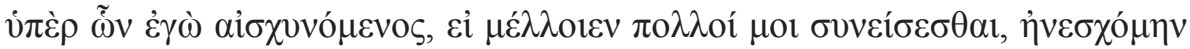
$\dot{\alpha} \delta$ iкoú $\mu \varepsilon v o s$.

En este proemio brilla con luz propia la impronta del $\tilde{\eta} \theta$ os, tan característica del estilo oratorio de Lisias. Consigue que de sus discursos se destilen varios rasgos - pertinentes para el juicio, por supuesto - de la personalidad de su defendido: las palabras escritas por Lisias parecen salir de la boca de un ciudadano probo y sencillo, ya maduro, ciertamente avergonzado por tener que hablar en público de cuestiones íntimas, y también algo ingenuo y confiado. Lisias consigue una adecuación perfecta entre el discurso que compone por encargo y el carácter del que lo debe leer en público, y se sirve de ella como potenciadora de la empatía del jurado. Desde el punto de vista de la moderna pragmática podría hacerse, sin duda, un interesante análisis de la polifonía de este discurso y sus instancias enunciadoras, pero excedería los límites fijados para este tipo de comentario retórico. Baste señalar la importancia que cobra para el proceso persuasivo la fuerza de ese autor implícito del que acabamos de hablar y que tan bien recrea Lisias.

El hecho de que esta segunda parte del proemio esté centrada en la propia persona que habla lo demuestra el predominio de la primera persona ver-

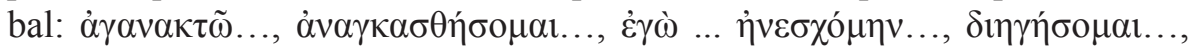

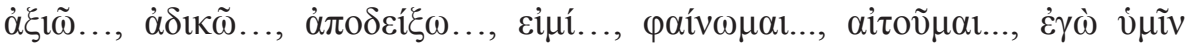
$\dot{\varepsilon} \pi \mathrm{i} \delta \varepsilon \dot{\xi} \xi \omega .$.

Una vez que el acusado cobra entidad personal y, admitiendo su bochorno, se hace tributario de crédito y empatía, debe hacerse con el favor de los jue-

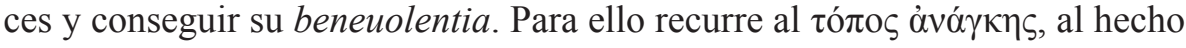
de que se ha visto forzado por las circunstancias a tomar parte en un juicio en

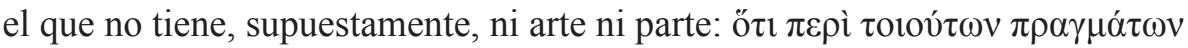

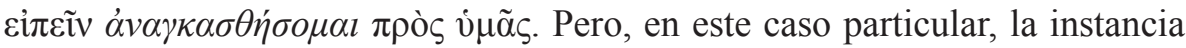
coactiva a la que nos remite el $\alpha v \alpha \gamma \kappa \alpha \sigma \theta \eta ́ \sigma o \mu \alpha \imath$ tiene nombre propio: Simón. Ante el $\tau$ ó $\pi$ oৎ del acusador como instigador injusto y malintencionado de un juicio que nunca debió celebrarse; así lo señala en la segunda oración del parágrafo tercero (la primera, como vimos, desarrollaba el tópico anterior):

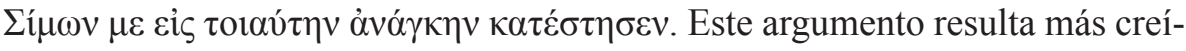
ble sobre el terreno ya labrado del vituperio de Simón que con tanta habilidad insinuó al comienzo del discurso.

Remata esta frase con un recurso propio también del iudicem docilem

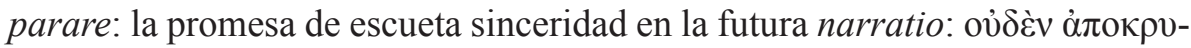

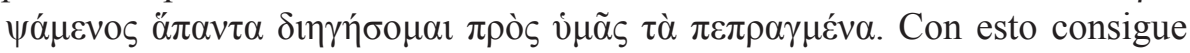


no sólo reforzar la paciencia y la atención del jurado (que se siente personalmente apelado con el $\pi \rho \grave{\varsigma} \varsigma \dot{v} \mu \tilde{\alpha} \varsigma$ ), sino que, además, fortalece su credibilidad

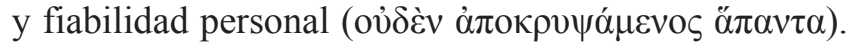

El punto cuarto comienza con la única súplica explícita de todo el proemio:

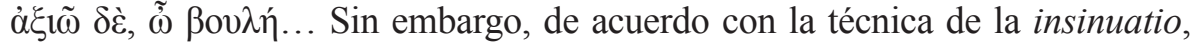
renuncia a pedir directamente la benevolencia de los jueces, y opta por soli-

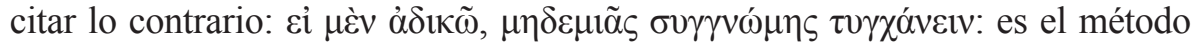
conocido por el nombre de dissimulatio ${ }^{16}$ con el que se consigue despertar la Eưvor $\alpha$ del jurado sin pedirla (o exhortando a que no se la concedan). La clave está en la impresión de seguridad en la propia causa que produce este tipo de formulaciones, que sirven, además, para atraer los ánimos del público a nuestra postura ante la coherencia personal atribuible al $\tilde{\hat{\eta}} \theta$ o

Pero enseguida introduce otra cláusula levemente adversativa con un $\delta \varepsilon ́$ correlativo, en la que matiza la afirmación anterior. En ella saca a colación la communis opinio sobre él y su conducta, para pasar a rebatirla con cal-

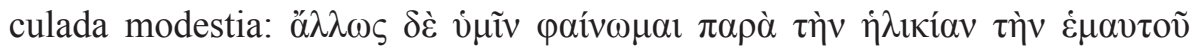

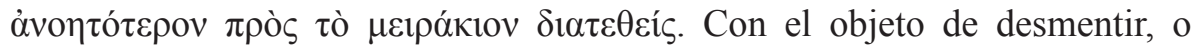
siquiera suavizar, esta afirmación deshonrosa, recurre a dos sententiae o rvó$\mu \alpha r$ con las que construye una especie de paralogismo o entimema (a decir de Aristóteles), cuya conclusión le es abiertamente favorable: $\alpha i \tau o \tilde{v} \mu \alpha \imath$ v $\mu \tilde{\alpha} \varsigma$

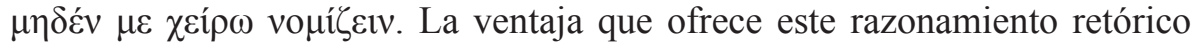
mediante sentencias es que, gracias al carácter general de éstas y a su aspecto de verdades irrefutables, pueden operar, si se eligen o crean adecuadamente, un cambio apreciable en la mentalidad de los oyentes. Además, al acuñarse específicamente para las necesidades de cada contexto, pueden llevar sibilinamente la conclusión del falso silogismo que constituyen a los derroteros deseados y más adecuados para la causa, y todo ello con gran aspecto de veracidad: basta con constatar que, en un caso como éste, se podrían haber aducido otras sentencias que nos guiaran a un resultado opuesto pero igualmente verosímil: v. gr. «El hombre justo antepone la prudencia a las pasiones». Como afirma Lausberg: «El carácter infinito y la función probatoria de la sententia proceden de que ésta, en el medio social de su esfera de validez y aplicación, tiene el valor de una sabiduría semejante en autoridad a un fallo judicial o a un texto legal y es aplicable a muchos casos concretos» ${ }^{17}$. Así, es

\footnotetext{
${ }^{16}$ Lausberg, Manual de Retórica, vol. I, p. 255.

${ }^{17}$ Ibíd., p. 269.
} 
el recurso más inteligente para desembarazarse del descrédito que pesa en su nombre, dado el carácter incontestable y universal de las $\gamma \nu \omega ́ \mu \alpha$.

Cada una de las dos cumple una función argumentativa implícita distinta

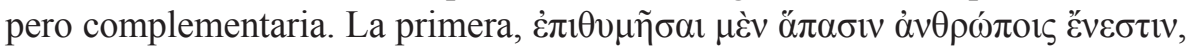
sirve para exculparle de haberse enamorado de un joven de tan baja condición (esclavo) y para justificar las locuras que pueda haber cometido por su amor: si enamorarse es propio de todos los hombres, ninguno de ellos puede escapar al amor, por lo que él está libre de responsabilidad al respecto y sencillamente actuó en consonancia con sus sentimientos (incontrolables). La segunda, oṽ $\tau$ ○

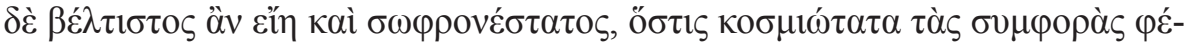
$\rho \varepsilon ı v \delta v ́ v \alpha \tau \alpha 1$, tiene el fin de restaurar su prestigio personal y su fama de probo ciudadano mediante un agudo juego de implicaturas: si el mejor y más sabio de los hombres será el que sea capaz de afrontar más dignamente las contrariedades de la vida, como él ha demostrado insistentemente en este proemio que está haciéndolo, se le debe tener por el más prudente y bondadoso. Qué duda cabe de que estos razonamientos serían absolutamente incapaces de pasar una prueba lógica al estilo de Aristóteles: pero lo que se persigue aquí no es eso, sino su poder persuasivo, su capacidad de convencer y de aparentar verosimilitud (cikós). El objetivo último de la retórica no es otro.

El proemio concluye con una escueta y sobria frase bisagra que da paso

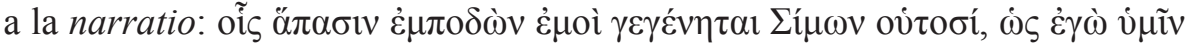
$\dot{\varepsilon} \pi \mid \delta \varepsilon i \xi \omega$. No hace falta señalar el cambio de actitud de los jueces hacia el acusado respecto al primer momento en que tomó la palabra: Lisias ha logrado hacerse con el auditorio y dar un giro a su hostilidad, sembrando por medio de la insinuatio una duda razonable en el corazón de los jueces sobre las supuestas buenas intenciones de Simón y restaurando, siquiera levemente, el maltratado prestigio de su defendido. Todo lo expuesto viene a confirmar la tan a menudo soslayada importancia de los mecanismos retóricos tácitos, negativos o irracionales, que, como la insinuatio o la dissimulatio, pueden erigirse en elementos determinantes para la construcción del discurso persuasivo en la Antigüedad Clásica.

Fecha de recepción de la primera versión del artículo: 10/09/2007

Fecha de aceptación del artículo: 13/06/2008

Fecha de recepción de la versión definitiva del artículo: 17/06/2008 